This work is licensed under a Creative Commons Attribution 3.0 License.

Research article

urn:1sid:zoobank.org:pub:6FF8835B-89F0-4EF9-B5A5-4F303C7F3263

\title{
Two new species of Yaginumaella (Araneae, Salticidae) from Wuling Mountain, China
}

\author{
Dan $\mathrm{LI}^{1}$, Cheng WANG ${ }^{2}$, Muhammad IRFAN ${ }^{3}$ \& Xian-Jin PENG ${ }^{4, *}$, \\ ${ }^{1,3,4}$ College of Life Sciences, Hunan Normal University, Changsha, \\ Hunan Province, 410081, P. R. China. \\ ${ }^{2}$ College of Biological and A\&F Engineering, Tongren University, Tongren, \\ Guizhou Province, 554300, P. R. China. \\ *Corresponding author: xjpeng@126.com \\ 1Email: 2653292236@qq.com \\ 2Email: 296064584@qq.com \\ ${ }^{3}$ Email: irfanuos94@yahoo.com \\ ${ }^{1}$ urn:lsid:zoobank.org:author:51EBD09A-214B-4A51-B37A-680B4F4CA6B7 \\ ${ }^{2}$ urn:1sid:zoobank.org:author:1F79A97E-8C35-48B1-BBEB-EA1A52D80EEB \\ ${ }^{3}$ urn:1sid:zoobank.org:author:81552C4A-93FC-4B6E-8EA1-0B4E38CC6466 \\ ${ }^{4}$ urn:1sid:zoobank.org:author:5CF67046-FAB4-43F1-AA72-ED2EB9741CD9
}

\begin{abstract}
The present paper deals with two new species, Yaginumaella pulchella sp. nov. and Yaginumaella hubeiensis sp. nov. Distributional data, as well as illustrations of body and copulatory organs, are provided. Descriptions of their morphology are given. The differences between the new species and their related taxa are discussed.
\end{abstract}

Keywords. Hubei, Hunan, jumping spider, Oriental region, taxonomy.

Li D., Wang C., Irfan M. \& Peng X.-J. 2018. Two new species of Yaginumaella (Araneae, Salticidae) from Wuling Mountain, China. European Journal of Taxonomy 488: 1-10. https://doi.org/10.5852/ejt.2018.488

\section{Introduction}

Yaginumaella Prószyński, 1979 was based on the type species Y. striatipes (Grube, 1861). So far, all the 46 species of Yaginumaella have been described from Asia (World Spider Catalog 2018). Eighteen species have been described from China (Prószyński 1979; Żabka 1980, 1981; Song \& Chai 1992; Xie \& Peng 1995; Yang et al. 1997; Peng et al. 2002, 2008; Zhu et al. 2005; Zhang \& Zhu 2007; Liu et al. 2016).

While we examined the specimens collected from Wuling Mountain (Hunan, Hubei), two new species of Yaginumaella were identified and are described here. 


\section{Material and methods}

All specimens were kept in 75\% ethanol, examined, measured and drawn with an Olympus SZX16 stereomicroscope and an Olympus BX53 compound microscope. Photos were taken with a digital camera Canon PowerShot G12 mounted on an Olympus SZX16. Compound focus images were generated using Helicon Focus software v. 3.10.

Leg measurements are given as total length (femur, patella plus tibia, metatarsus, tarsus). Specimens are deposited at the College of Life Sciences, Hunan Normal University (HNU).

\section{Abbreviations}

$\begin{array}{lll}\mathrm{AER} & = & \text { anterior eye row } \\ \mathrm{ALE} & = & \text { anterior lateral eyes } \\ \mathrm{AME} & = & \text { anterior median eyes } \\ \mathrm{CD} & = & \text { copulatory ducts } \\ \mathrm{CO} & = & \text { copulatory opening } \\ \mathrm{E} & = & \text { embolus } \\ \mathrm{EFL} & = & \text { eye diameter } \\ \mathrm{EP} & = & \text { epigynal pocket } \\ \mathrm{PB} & = & \text { palpal bulbus } \\ \mathrm{PER} & = & \text { posterior eye row } \\ \mathrm{PLE} & = & \text { posterior lateral eyes } \\ \mathrm{TA} & = & \text { tibial apophysis }\end{array}$

\section{Results}

Class Arachnida Cuvier, 1812

Order Araneae Clerck, 1757

Family Salticidae Blackwall, 1841

Genus Yaginumaella Prószyński, 1979

Yaginumaella pulchella sp. nov. urn:1sid:zoobank.org:act:84997381-7EE8-4A26-88B4-83B84881487B

Figs $1-2$

\section{Differential diagnosis}

The new species resembles Y. falcata Zhu et al., 2005, but can be distinguished by: (1) palpal bulbus about two times longer than wide (Figs 1B, 2A) vs about 1.3 times longer than wide in Y. falcata in ventral view, (2) embolus originating from the position of 9:00 o'clock (Figs 1B, 2A) vs 8:00 o'clock in $Y$. falcata in ventral view, (3) tibial apophysis almost straight (Figs 1C, 2B) vs distinctly recurved in Y. falcata in retrolateral view, (4) epigynal pockets below the copulatory opening (Figs 1E, 2C) vs almost equal to the copulatory opening in Y. falcata, and (5) the course of copulatory ducts also different (Figs 1F, 2D).

\section{Etymology}

The specific name comes from the Latin adjetive pulchellus, - $a$, - um (diminutive of pulcher), meaning "beautiful little", and referring to the distinct marking on the dorsal side of the abdomen. 

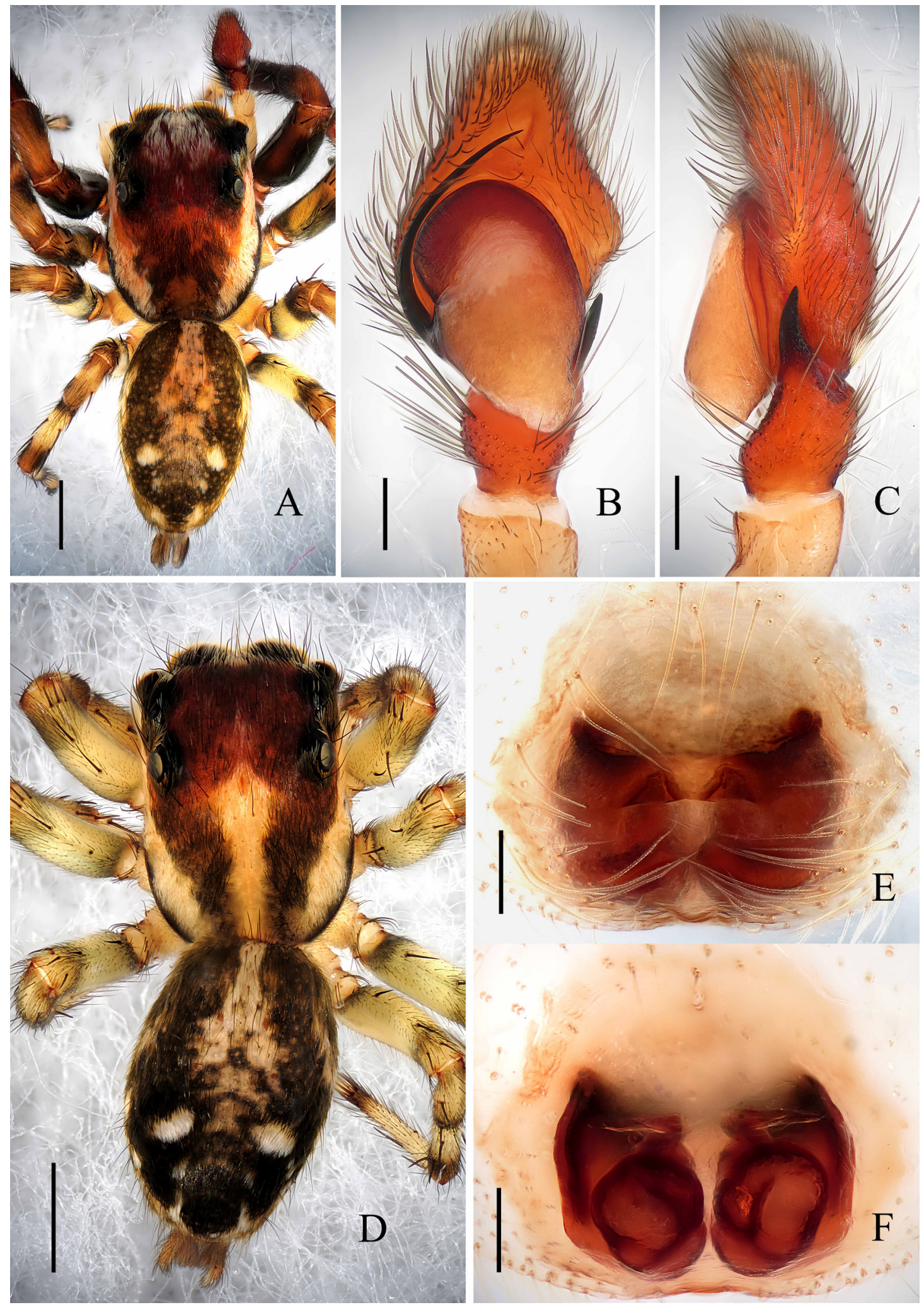

Fig. 1. Yaginumaella pulchella sp. nov. A-C. Holotype, ô (HNU-HN-IV-1417-02). D-F. Paratype, $q$ (HNU-HN-IV-1417-02). A. Male body, dorsal view. B. Male palp, ventral view. C. Male palp, retrolateral view. D. Female body, dorsal view. E. Epigyne, ventral view. F. Vulva, dorsal view. Scale bars: A, D = $1 \mathrm{~mm}$; B-C, E-F $=0.2 \mathrm{~mm}$. 


\section{Type material}

\section{Holotype}

CHINA: $1 \partial^{\lambda}$, Hunan, Changde City, Shimen County, Hupingshan Township, Daling Village, $30^{\circ} 02^{\prime} 02^{\prime \prime} \mathrm{N}$, $110^{\circ} 37^{\prime} 30^{\prime \prime}$ E, 436 m a.s.1., 20 Oct. 2014, Cheng Wang, Bing Zhou, Jiahui Zhou, and Yuhui Gong leg. (HNU-HN-IV-1417-02).

\section{Paratype}

CHINA: 1 , , Hunan, Changde City, Shimen County, Hupingshan Township, Daling Village, $30^{\circ} 02^{\prime} 02^{\prime \prime} \mathrm{N}$, $110^{\circ} 37^{\prime} 30^{\prime \prime}$ E, 436 m a.s.l., 20 Oct. 2014, Cheng Wang, Bing Zhou, Jiahui Zhou, and Yuhui Gong leg. (HNU-HN-IV-1417-02).

\section{Description}

Male (holotype)

Total length $6.08 \mathrm{~mm}$. Cephalothorax $3.01 \times 2.04 \mathrm{~mm}$. Abdomen $2.081 \times 1.91 \mathrm{~mm}$. Eye sizes and interdistances: AME $0.67 \mathrm{~mm}$, ALE $0.37 \mathrm{~mm}$, PLE $0.39 \mathrm{~mm}$, AER $2.07 \mathrm{~mm}$, PER $1.95 \mathrm{~mm}$, EFL $1.41 \mathrm{~mm}$. Carapace brown to orange in color followed by a pair of longitudinal white hairs band on lateral sides; median ocular area provided with a round patch of white hairs. Basal area of each eye, anterior, and lateral margins of ocular area black with black hairs. Thoracic region flat. Fovea short and longitudinal. Chelicerae yellowish-brown, two pro-marginal and one retro-marginal tooth. Endites longer than wide, yellowish-brown. Labium ligulate with thick hairs, terminal area lightly colored. Sternum almost oval, covered with yellow hairs. Legs yellowish-brown, terminal areas darker in I and II. Measurements of legs: I $6.70 \mathrm{~mm}(2.10 \mathrm{~mm}, 2.75 \mathrm{~mm}, 1.15 \mathrm{~mm}, 0.70 \mathrm{~mm})$, II $5.61 \mathrm{~mm}(1.71 \mathrm{~mm}, 2.18 \mathrm{~mm}, 1.02 \mathrm{~mm}$, $0.70 \mathrm{~mm})$, III $6.37 \mathrm{~mm}(2.04 \mathrm{~mm}, 2.20 \mathrm{~mm}, 1.31 \mathrm{~mm}, 0.82 \mathrm{~mm})$, IV $6.54 \mathrm{~mm}(2.12 \mathrm{~mm}, 2.30 \mathrm{~mm}$, $1.39 \mathrm{~mm}, 0.83 \mathrm{~mm}$ ). Leg formula: 1432. Abdomen oval, yellowish-green with lighter yellowish central area, followed by the longitudinal greenish band on lateral areas and transversally in the posterior,
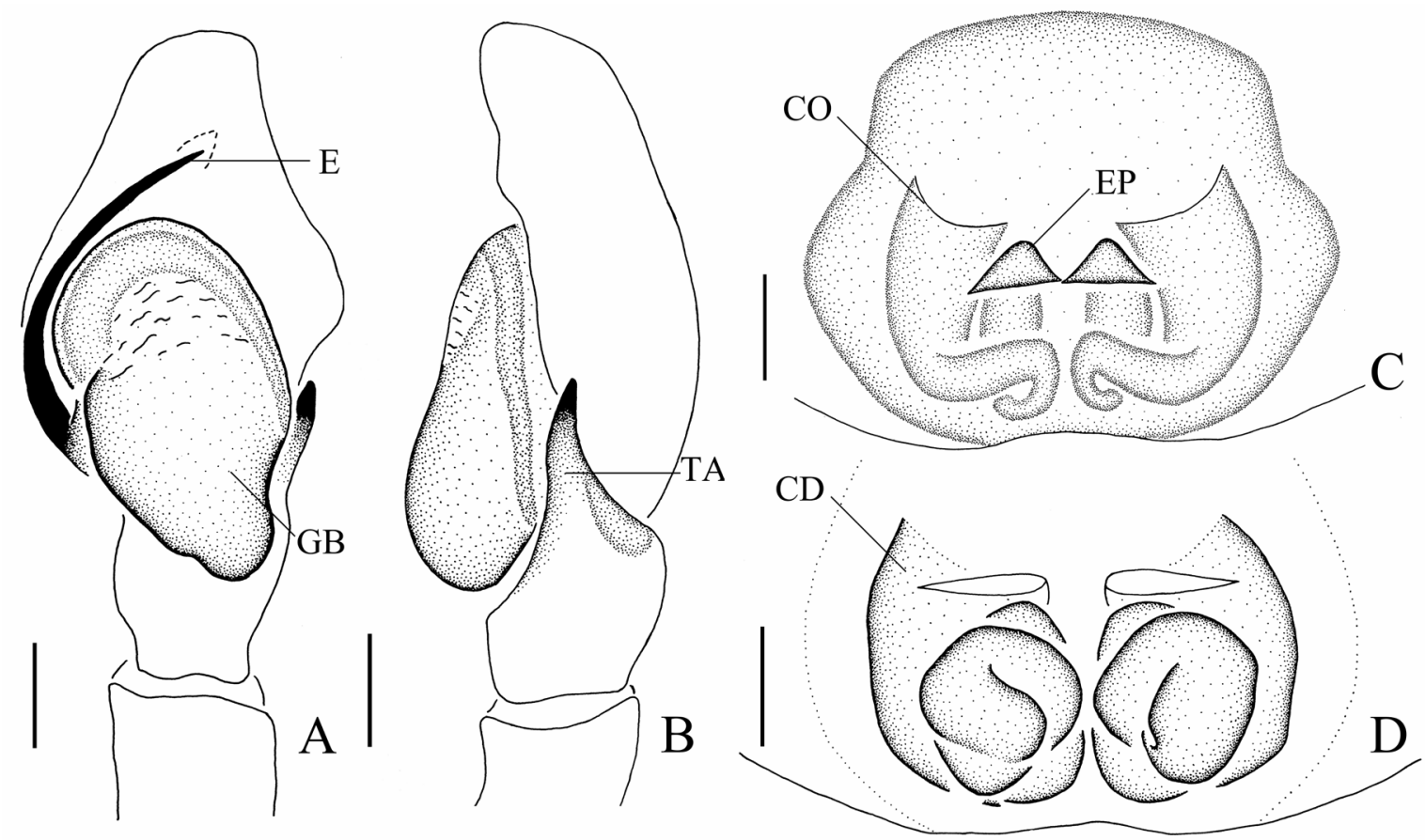

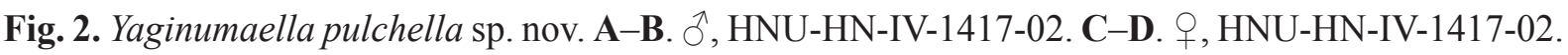
A. Male palp, ventral view. B. Male palp, retrolateral view. C. Epigyne, ventral view. D. Vulva, dorsal view. Scale bars: $0.2 \mathrm{~mm}$. 
muscular impressions distinct, posterior area with a pair of white circular patches, lateral areas scattered with three pairs of small white patches. Venter light yellow, scattered with black patches, median area with one longitudinal dark brown stripe. Palp (Figs 1B-C, 2A-B): tibia longer than wide, terminal part of the tibial apophysis recurved in retrolateral view. Palpal bulbus with a membranous structure at the center. Embolus almost as long as palpal bulbus, originated from the position of 9:00 o'clock. Palpal bulbus about two times longer than wide in ventral view. Sperm duct robust.

Female (paratype)

Total length $5.38 \mathrm{~mm}$. Cephalothorax $2.57 \times 1.48 \mathrm{~mm}$. Abdomen $2.71 \times 1.86 \mathrm{~mm}$. Clypeus height $0.13 \mathrm{~mm}$. Eye sizes and interdistances: AME $0.57 \mathrm{~mm}$, ALE $0.34 \mathrm{~mm}$, PLE $0.33 \mathrm{~mm}$, AER $1.81 \mathrm{~mm}$, PER $1.67 \mathrm{~mm}$, EFL $1.29 \mathrm{~mm}$. Carapace similar to male but slightly more reddish, with two longitudinal white stripes at the lateral sides and, a centeral white band extending from the posterior margin of ocular area to the posterior margin of carapace. Legs pale yellow, terminal areas darker with annuli in III and IV. Measurements of legs: I $4.31 \mathrm{~mm}(1.51 \mathrm{~mm}, 1.54 \mathrm{~mm}, 0.66 \mathrm{~mm}, 0.60 \mathrm{~mm})$, II $4.38 \mathrm{~mm}$ $(1.52 \mathrm{~mm}, 1.61 \mathrm{~mm}, 0.65 \mathrm{~mm}, 0.60 \mathrm{~mm})$, III $5.31 \mathrm{~mm}(1.70 \mathrm{~mm}, 1.75 \mathrm{~mm}, 1.05 \mathrm{~mm}, 0.81 \mathrm{~mm})$, IV $5.53 \mathrm{~mm}(1.65 \mathrm{~mm}, 1.82 \mathrm{~mm}, 1.25 \mathrm{~mm}, 0.81 \mathrm{~mm})$. Leg formula: 4321 . The morphological characters of abdomen as same as in male except darker in color. Epigyne (Figs 1E-F, 2C-D): epigynal pockets present ventromesially. Copulatory opening almost slit-shaped. Copulatory ducts short and stout.

\section{Distribution}

Hunan (China) (Fig. 3).

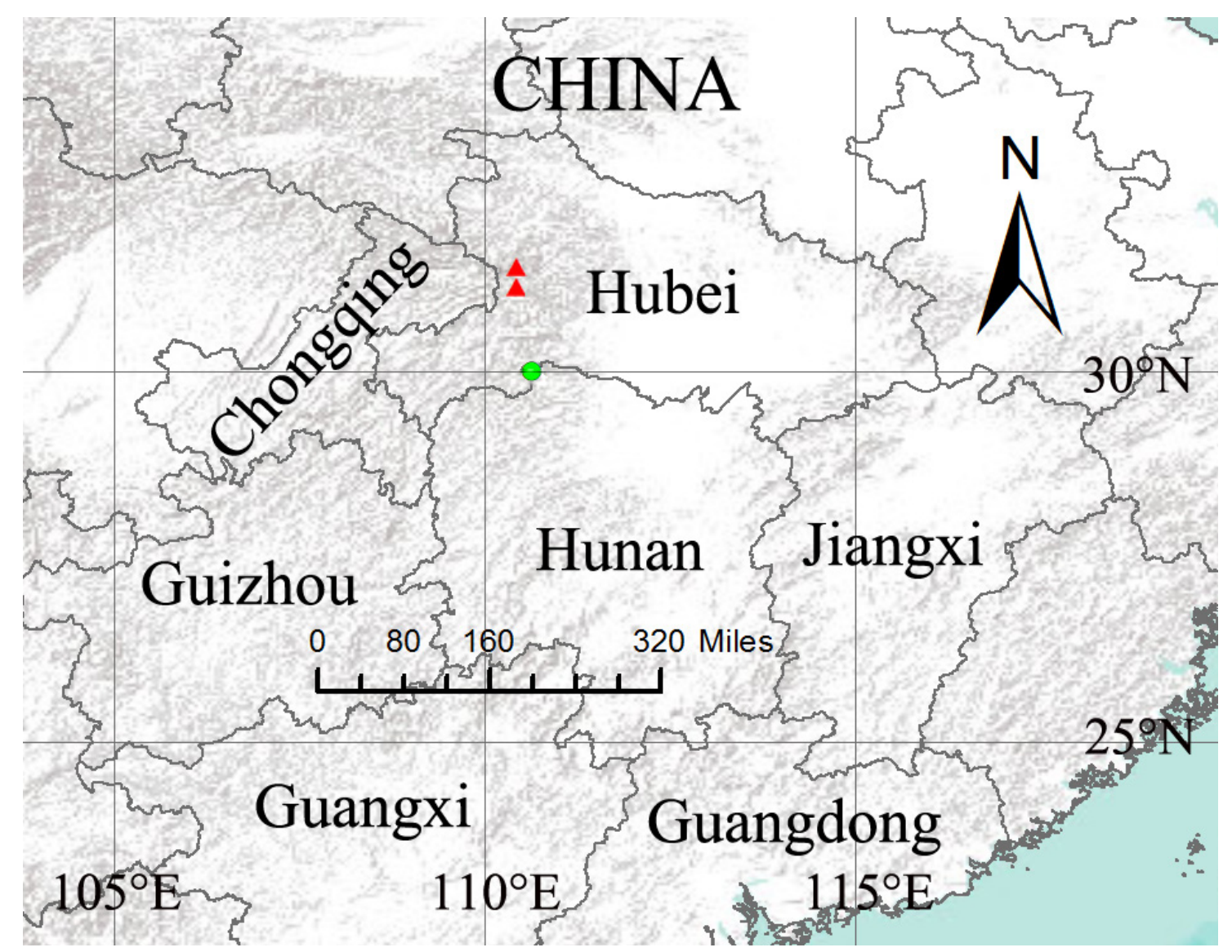

Fig. 3. Distribution records of Yaginumaella hubeiensis sp. nov. (red triangles) and Y. pulchella sp. nov. (green dot). 


\section{Yaginumaella hubeiensis sp. nov. urn:lsid:zoobank.org:act:D0435849-EE26-4C0A-8BF8-A064FF439B32}

Figs $4-5$

\section{Differential diagnosis}

The new species resembles $Y$. pulchella sp. nov., but can be distinguished by: (1) embolus much longer than the palpal bulbus, originating from the position of 7:00 o'clock (Figs 4B, 5A) vs as long as palpal bulbus, and originating from the position of 9:00 o'clock in Y. pulchella sp. nov. (Figs 1B, 2A) in ventral view, (2) palpal bulbus slightly wider anteriorly, depressed posteriorly (Figs 4B, 5A) vs much wider anteriorly and bulging posteriorly in Y. pulchella sp. nov. (Figs 1B, 2A) in ventral view, (3) the visible portion of the sperm duct originates from the posterior portion of the palpal bulbus (Figs 4B, 5A) vs from the anterior portion of the palpal bulbus in Y. pulchella sp. nov. (Figs 1B, 2A) in ventral view, (4) epigynal pockets bell-shaped, longer than wide, and separated from each other for more than four times of epigynal pocket width (Figs 4E, 5C) vs as long as wide, and almost touching each other in Y. pulchella sp. nov. (Figs 1E, 2C), (5) copulatory opening "()"-shaped and longitudinal (Figs 4E, 5C) vs slit-shaped and diagonal in Y. pulchella sp. nov. (Figs 1E, 2C), and (6) the course of the copulatory ducts is also different (Figs 4F, 5D).

\section{Etymology}

The specific name comes from the type locality.

\section{Type material}

Holotype

CHINA: 1 $\widehat{\jmath}$, Hunan, Changde City, Shimen County, Hupingshan Township, Daling Village, $30^{\circ} 20^{\prime} 26^{\prime \prime} \mathrm{N}, 110^{\circ} 24^{\prime} 47^{\prime \prime}$ E, 1320 m a.s.1., 26 Apr. 2016, Wang Liu, Chen Zen, and Tian Tian leg. (HNU-HB-IV-1626).

\section{Paratypes}

CHINA: 9 ô, Hunan, Changde City, Shimen County, Hupingshan Township, Daling Village, $30^{\circ} 20^{\prime} 26^{\prime \prime} \mathrm{N}, 110^{\circ} 24^{\prime} 47^{\prime \prime}$ E, 1320 m a.s.1., 26 Apr. 2016, Wang Liu, Chen Zen, and Tian Tian leg. (HNU-HB-IV-1626); 3 ㅇ, Hubei, Enshi City, Badong County, Yanduhe Township, Songziyuan Village, $31^{\circ} 24^{\prime} 1^{\prime \prime}$ N, $110^{\circ} 23^{\prime} 57^{\prime \prime}$ E, 1836 m a.s.1., 24 Apr. 2016, Wang Liu, Chen Zen, and Tian Tian leg. (HNUHB-IV-1624).

\section{Description}

Male (holotype)

Total length $6.98 \mathrm{~mm}$. Cephalothorax $3.28 \times 2.44 \mathrm{~mm}$. Abdomen $3.49 \times 2.03 \mathrm{~mm}$. Eye sizes and interdistances: AME $0.63 \mathrm{~mm}$, ALE $0.34 \mathrm{~mm}$, PLE $0.18 \mathrm{~mm}$. AER $2.06 \mathrm{~mm}$, PER $1.82 \mathrm{~mm}$, EFL $1.38 \mathrm{~mm}$. Carapace reddish brown, with three longitudinal yellowish-brown stripes on the median and two on the lateral areas (extending from the posterior margin of the ocular area to posterior margin of carapace). Lateral areas densely covered with longitudinal white hairs strips. Central area lightly colored. The base of each eye, anterior and lateral margins of ocular area black with black hairs. Thoracic region flat, fovea longitudinal, shallow, and indistinct. Cervical and radial grooves distinct. Sternum oval, covered with short brown hairs, central area bulged. Chelicerae yellowish-brown, two pro-marginal and one retro-marginal tooth. Legs yellowish-brown with annuli, terminal area darker. Measurements of legs: I $7.35 \mathrm{~mm}(2.52 \mathrm{~mm}, 2.82 \mathrm{~mm}, 1.28 \mathrm{~mm}, 0.73 \mathrm{~mm})$, II $5.87 \mathrm{~mm}(2.04 \mathrm{~mm}, 2.43 \mathrm{~mm}, 0.89 \mathrm{~mm}$, $0.51 \mathrm{~mm})$, III $6.03 \mathrm{~mm}(2.26 \mathrm{~mm}, 2.32 \mathrm{~mm}, 0.85 \mathrm{~mm}, 0.60 \mathrm{~mm})$, IV $6.96 \mathrm{~mm}(2.30 \mathrm{~mm}, 2.42 \mathrm{~mm}$, $1.54 \mathrm{~mm}, 0.70 \mathrm{~mm}$ ). Leg formula: 1432. Abdomen oval, dark brown with lighter yellowish central area with inclined white stripes, followed by the longitudinal dark band on lateral areas and transversally 

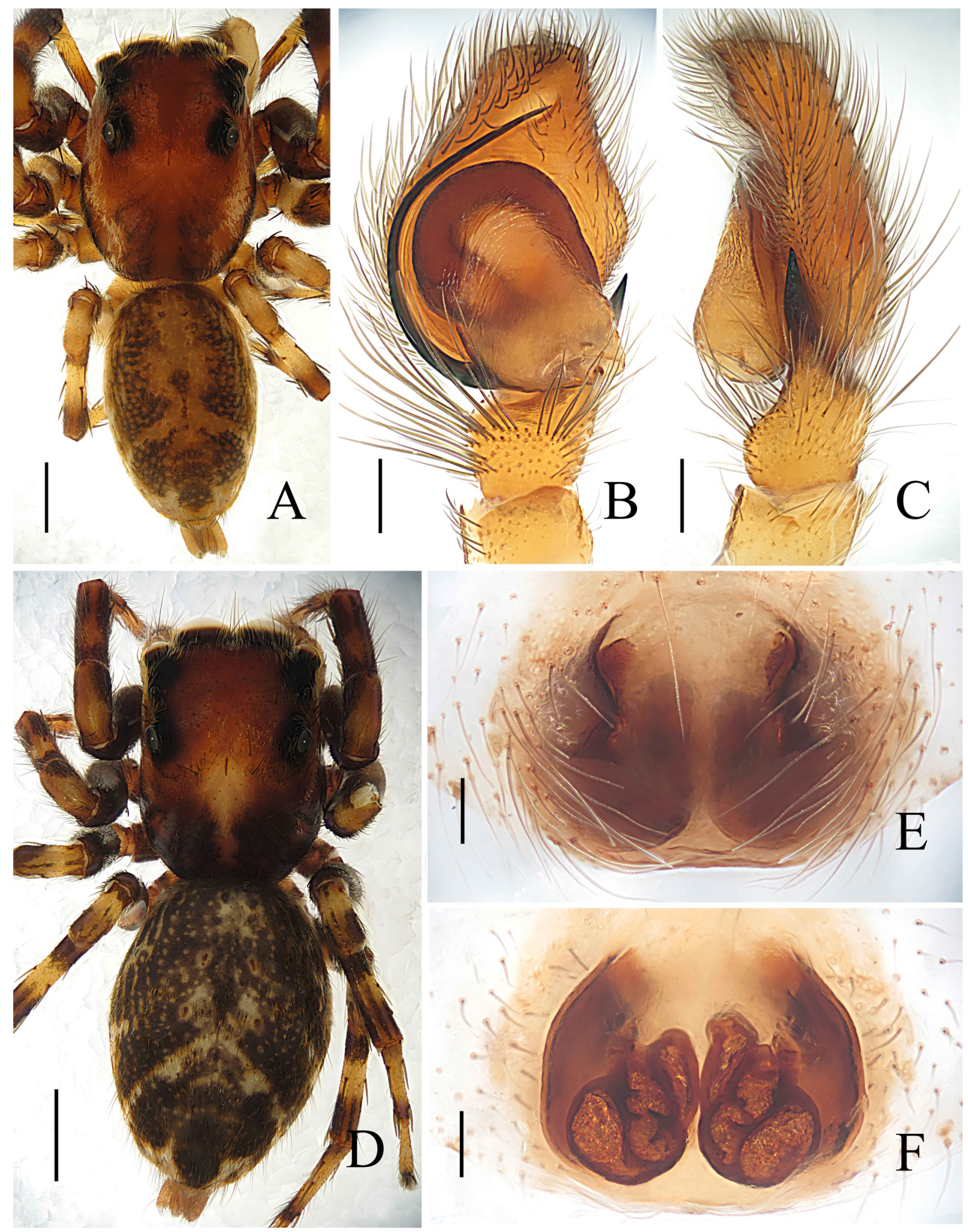

Fig. 4. Yaginumaella hubeiensis sp. nov. A-C. Holotype, đ̊ (HNU-HB-IV-1626). D-F. Paratype, $q$ (HNU-HB-IV-1624). A. Male body, dorsal view. B. Male palp, ventral view. C. Male palp, retrolateral view. D. Female body, dorsal view. E. Epigyne, ventral view. F. Vulva, dorsal view. Scale bars: A, D = $1 \mathrm{~mm} ; \mathrm{B}-\mathrm{C}, \mathrm{E}-\mathrm{F}=0.2 \mathrm{~mm}$. 
in the posterior, dorsum scattered with lots of white and grayish-black patches, lateral area two pairs of muscular impressions distinct. Venter white, scattered with black patches, median area with one longitudinal dark brown stripe. Palp (Figs 4B-C, 5A-B): tibia thick, terminal part of the tibial apophysis straight in retrolateral view. Palpal bulbus slightly wider anteriorly, with a membranous structure at the center, posterior end with a deep depression. Embolus bow-shaped, much longer than the palpal bulbus, originated from the position of 7:00 o'clock. Sperm ducts robust. Variation: total length 5.97-6.98 mm $(n=10)$.

\section{Female}

Total length $6.34 \mathrm{~mm}$. Cephalothorax $2.59 \times 1.91 \mathrm{~mm}$. Abdomen $3.55 \times 2.33 \mathrm{~mm}$. Clypeus height $0.09 \mathrm{~mm}$. Eye sizes and interdistances: AME $0.48 \mathrm{~mm}$, ALE $0.24 \mathrm{~mm}$, PLE $0.22 \mathrm{~mm}$. AER $1.82 \mathrm{~mm}$, PER $1.67 \mathrm{~mm}$, EFL $1.19 \mathrm{~mm}$. Carapace the same as male except dark colored. Carapace yellowishbrown. Legs light yellow, terminal areas darker with annuli in III and IV. I and II darker than III and IV. Measurements of legs: I $4.52 \mathrm{~mm}(1.42 \mathrm{~mm}, 1.87 \mathrm{~mm}, 0.69 \mathrm{~mm}, 0.54 \mathrm{~mm})$, II $4.05 \mathrm{~mm}(1.51 \mathrm{~mm}$, $1.59 \mathrm{~mm}, 0.58 \mathrm{~mm}, 0.37 \mathrm{~mm})$, III $4.27 \mathrm{~mm}(1.61 \mathrm{~mm}, 1.25 \mathrm{~mm}, 0.97 \mathrm{~mm}, 0.44 \mathrm{~mm})$, IV $4.85 \mathrm{~mm}$ $(1.66 \mathrm{~mm}, 1.81 \mathrm{~mm}, 0.98 \mathrm{~mm}, 0.40 \mathrm{~mm})$. Leg formula: 4321 . The other morphological characters of abdomen as same as male except darker in color. Epigyne (Figs 4E-F, 5C-D): epigynal pockets bell-shaped, longer than wide, present ventrolaterally. Copulatory opening slit-shaped and diagonal. Variation: Total length 4.81-6.76 mm $(\mathrm{n}=3)$.

\section{Distribution}

Hubei (China) (Fig. 3).
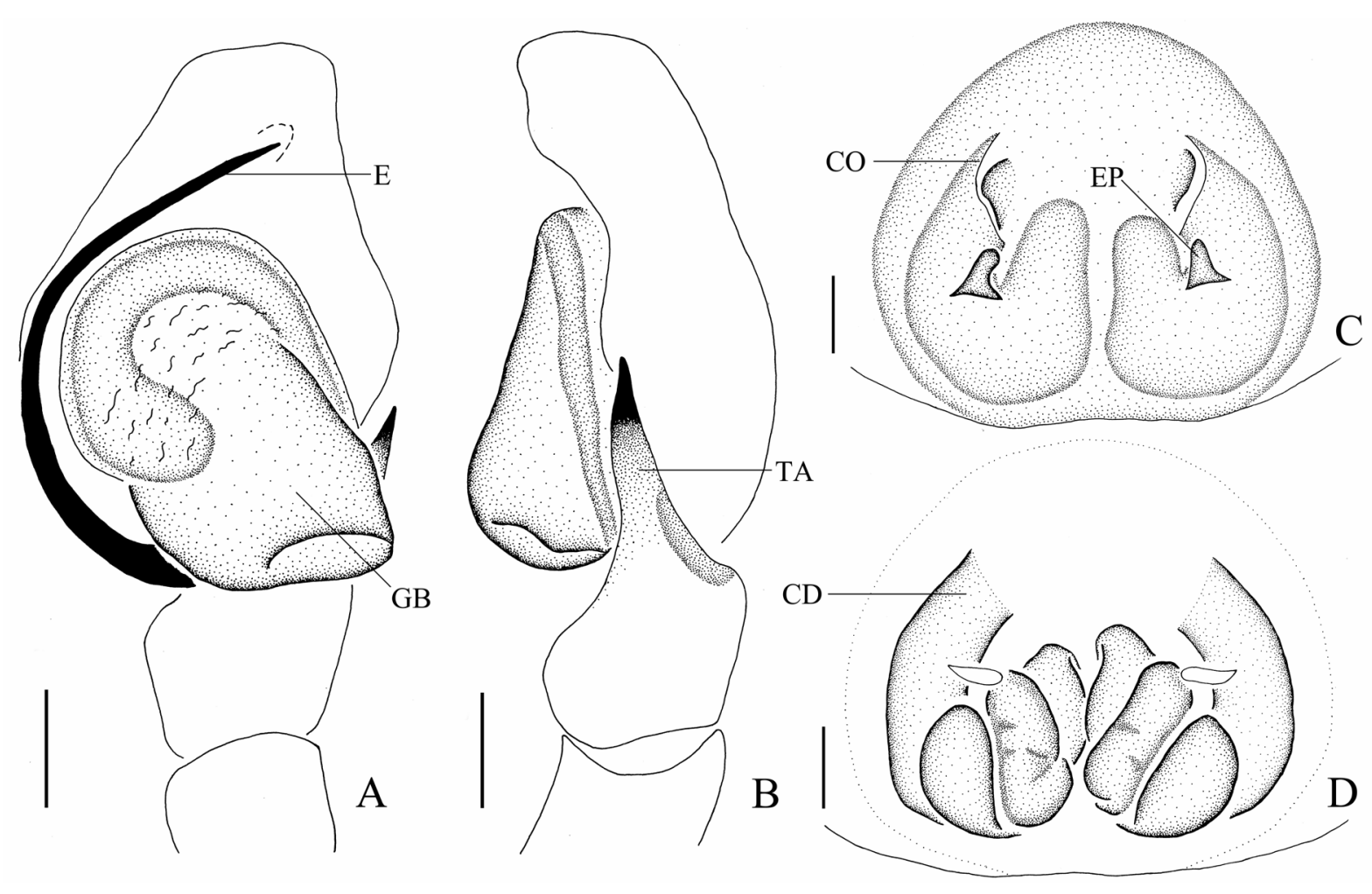

Fig. 5. Yaginumaella hubeiensis sp. nov. A-B. ふૈ, HNU-HB-IV-1626. C-D. શ, HNU-HB-IV-1624. A. Male palp, ventral view. B. Male palp, retrolateral view. C. Epigyne, ventral view. D. Vulva, dorsal view. Scale bars: $0.2 \mathrm{~mm}$. 


\section{Discussion}

The genus Yaginumaella is placed under the subtribe Plexippina (Maddison, 2015) of subfamily Salticinae (Maddison, 2015) (Maddison 2015). Currently, a total of 46 species have been described mainly from subtropical Bhutan, China, India, Japan, Korea, Myanmar, Nepal, and Russia (World Spider Catalog 2018), and Ptocasius (Simon, 1885) only contains 13 species described from China, India, Kazakhstan, Myanmar, Singapore, Sri Lanka, and Vietnam (World Spider Catalog 2018). Most of the taxonomists have reported that Yaginumaella is closely similar to, and may well be synonymous with, Ptocasius (Żabka 1985; Song 1991; Hu 2001; Sunil 2013; Logunov \& Jäger 2015), in particular, the characteristics of the female are so close that it is difficult to distinguish. Even many scholars think it should be merged. So far, as there is no particular consensus, they are considered two separate genera. In future, many species will need to be transferred depending on taxonomic revisions. But, based on the characteristics of specimens checked by the authors, together with those illustrated in literature, we think the two genera can be diagnosed as: (1) thoracic region steep in Ptocasius vs flat in Yaginumaella; (2) carapace with a transverse stripe in Ptocasius vs a pair of longitudinal dark bands extending from back of ALE to retromargin in Yaginumaella; (3) abdomen with transverse stripes in Ptocasius vs usually with longitudinal stripes in Yaginumaella; (4) embolus two times longer than palpal bulbus, originating from the right margin of the palpal bulbus, and palpal bulbus without posterior lobe in Ptocasius vs as long as palpal bulbus, originating from the left margin of the palpal bulbus, and palpal bulbus with posterior lobe in Yaginumaella. Because of this, the two new species we describe fit the characteristics of Yaginumaella.

\section{Acknowledgments}

We are grateful to Bing Zhou, Jiahui Gan, Yuhui Gong, Wang Liu, Chen Zen, and Tian Tian for collecting the specimens. This research was sponsored by the National Special Fund on Basic Research of Science and Technology of China (No. 2014FY110100). It is also partly supported by the National Natural Sciences Foundation of China (NSFC-30970327, 31272271, 31272272, 31301861), the Hunan Provincial Program for Development of Key Disciplines in Ecology (grant No. 0713), the Science and Technology Foundation of Guizhou Province (No. J(2012)2313), the Doctoral Foundation of Tongren University (DS1101), Hunan Provincial Natural Science Foundation of China (No.11JJ1004/12JJ3028), Program for New Century Excellent Talents in University (NCET-12-0717), China Postdoctoral Science Foundation (No. 20100471221/201104506), and the program of Hunan Provincial Science and Technology Plans (No. 2010RS4006).

\section{References}

Hu J.L. 2001. Spiders in Qinghai-Tibet Plateau of China. Henan Science and Technology Publishing House, Henan.

Liu W, Yang S.-F. \& Peng X.-J. 2016. Two new species of Yaginumaella, Prószyński 1979 from Yunnan, China (Araneae, Salticidae). ZooKeys 620: 57-66. https://doi.org/10.3897/zookeys.620.7895

Logunov D.V. \& Jäger P. 2015. Spiders from Vietnam (Arachnida: Aranei): new species and records. Russian Entomological Journal 24 (4): 343-363.

Maddison W.P. 2015. A phylogenetic classification of jumping spiders (Araneae: Salticidae). Journal of Arachnology 43 (3): 231-292. https://doi.org/10.1636/arac-43-03-231-292

Peng X.-J., Tso I.M. \& Li S.Q. 2002. Five new and four newly recorded species of jumping spiders from Taiwan (Araneae: Salticidae). Zoological Studies 41: 1-12.

Peng X.-J., Tang G. \& Li S.Q. 2008. Eight new species of salticids from China (Araneae, Salticidae). Acta Zootaxonomica Sinica 33: 248-259. 
Prószyński J. 1979. Systematic studies on East Palearctic Salticidae III. Remarks on Salticidae of the USSR. Annales Zoologici, Warszawa 34: 299-369.

Song D.X. 1991. Three new species of the genus Ptocasius from China (Araneae: Salticidae). Sinozoologia 8: 163-168.

Song D.X. \& Chai J.Y. 1992. On new species of jumping spiders (Araneae: Salticidae) from Wuling Mountains area, southwestern China. Journal of Xinjiang University 9 (3): 76-86.

Sunil J.K. 2013. New species of Yaginumaella Proszynski from India (Araneae: Salticidae). Munis Entomology and Zoology 8 (1): 63-66.

World Spider Catalog 2018. World Spider Catalog. Natural History Museum Bern. Version 19.0. Available from: http://wsc.nmbe.ch [accessed 3 Jul. 2018].

Xie L.P. \& Peng X.-J. 1995. Four species of Salticidae from southern China (Arachnida: Araneae). Acta Zootaxonomica Sinica 20: 289-294.

Yang Y.T., Tang Y.Q. \& Kim J.P. 1997. A new species of genus Yaginumaella (Araneae [sic]: Salticidae) from China. Korean Arachnology 13 (1): 47-49.

Żabka M. 1980. Salticidae from the Nepal Himalayas. New species of Yaginumaella Prószyński 1979 (Arachnida: Araneae). Senckenbergiana Biologica 60: 371-380.

Żabka M. 1981. New species of Yaginumaella Prószyński 1979 and Helicius Prószyński 1976 (Araneae, Salticidae) from Bhutan and Burma. Entomologica Basiliensis 6: 5-41.

Żabka M. 1985. Systematic and zoogeographic study on the family Salticidae (Araneae) from VietNam. Annales Zoologici, Warszawa 39: 197-485.

Zhang B.S. \& Zhu M.S. 2007. Anew species of the genus Yaginumaella from China (Araneae: Salticidae). Journal of Dali University 6: 1-2.

Zhu M.S., Zhang J.X., Zhang Z.S. \& Chen H.M. 2005. Arachnida: Araneae. In: Yang M.F. \& Jin D.C. (eds) Insects from Dashahe Nature Reserve of Guizhou: 534-543. Guizhou People's Publishing House, Guiyang.

Manuscript received: 9 July 2018

Manuscript accepted: 7 November 2018

Published on: 18 December 2018

Topic editor: Rudy CAM Jocque, Ph.D.

Desk editor: Alejandro Quintanar

Printed versions of all papers are also deposited in the libraries of the institutes that are members of the EJT consortium: Muséum national d'Histoire naturelle, Paris, France; Meise Botanic Garden, Belgium; Royal Museum for Central Africa, Tervuren, Belgium; Natural History Museum, London, United Kingdom; Royal Belgian Institute of Natural Sciences, Brussels, Belgium; Natural History Museum of Denmark, Copenhagen, Denmark; Naturalis Biodiversity Center, Leiden, the Netherlands; Museo Nacional de Ciencias Naturales-CSIC, Madrid, Spain; Real Jardín Botánico de Madrid CSIC, Madrid, Spain; Zoological Research Museum Alexander Koenig, Bonn, Germany. 